The trial trenches that have been dug have revealed that the deposits consist of lake beds alternating with land surfaces. Upon four of the land surfacesor layers - exposed, there are abundant signs of occupation by Acheulean man, and very large numbers of hand-axes, eleavers and bolas stones have been found closely associated with the fossilized remains of extinct animals. Another discovery of importance is the finding of another occupatior floor that represents the first well-authenticated evidence of the existence of a flake-culture people anywhere in East Africa, in the deposits of the Middle Pleistocene. The animal fossils found include those of extinct species of elephant, hippopotamus, giraffe and rhinoceros, a baboon that was as big as a gorilla, and a pig that was as large as a present-day rhinoceros. The Kenya Government has fenced the site, and it is proposed that the various occupation floors shall be exposed and then roofed so that visitors can see the implements and fossils lying in position.

\section{Science and the War}

A symposrum of papers presented at the seventy. fifth anniversary meeting of the Kansas Academy of Science on April 10, 1943, has now been reprinted (Trans. Kansas Academy of Science, 46) under the title "Science and the War". L. E. Cull deals with the place of food and J. H. MeMillan with that of physics in the war effort. The latter points out that when Japan began hostilities, the United States had nearly two hundred physicists directing about five hundred professional physicists, investigating specific war problems. This represented about seventythree per cent of the physicists in the United States who were judged capable and free to carry on this type of work. Both in government research laboratories and in industry there has been an acute shortage of physicists, and the programme for training war-time physicists does not appear to have been so well organized as that for research. N. P. Sherwood's paper on "Bacteriology, Medicine and the War" emphasizes the marked advance in our know. ledge and resources since 1928 for dealing with wound infections, venereal disease, typhoid and tetanus, etc.

J. W. Greene, discussing "Chemistry and the War Effort", briefly reviews the familiar achievements of the chemist in such fields as explosives, synthetic rubber, plastics, fertilizers, aviation spirit, solvents, synthetic organic chemicals, etc. "The Role of Botany in War-time" is outlined by P. B. Sears, who refers to the services of botanists in camouflage work, cotton fibre problems, plant breeding and control of disease, the preparation of airfield runways with sod covers which will prevent erosion, and particularly in food production. J. C. Frye and C. P. Kaiser's paper, "Geology in the Present War", refers to the services of the geologist in meeting difficulties in the supply of strategic minerals and other raw materials, domestic water supplies, and in mapping. J. Breukelman deals with the "Relation of Zoology to the War Effort", and refers in particular to its contribution in the field of nutrition, in pest control, in jungle warfare and in the conservation of fauna. The final paper, by H. B. Reed on "Some Contributions of Psychology toward the War Effort", after referring to the neglect of psychology after 1918 by the Armed Forces, indicates the value of the psychologist in placing men in the activities for which they are best qualified and in which they may be of the greatest service to the country, in devising technique for effective training in the skills required in military work or for building up civilian and military morale and propaganda effects, in handling and dealing with children in bombed areas, and in the effective care of war orphans. A brief account of the classification work in the U.S. Army is included.

\section{William H. Nichols Medal of the American Chem- ical Society: Award to Prof. C. S. Marvel}

THE William H. Nichols Medal for 1944 of the New York Section of the American Chemical Society has been presented to Prof. Carl Shipp Marvel for outstanding contributions to knowledge of the structure of vinyl polymers, the long-chain molecules used as rubber substitutes, in production of plastics, and as thickening and blending agents in chemical manufacturing, and for his research in the structure of sulphur dioxide - olefin polymers. Prof. Marvel is professor of organic chemistry at the University of Illinois, and president-elect of the American Chemical Society. As a graduate student at the University of Illinois, Prof. Marvel became interested during the War of 1914-18 in the development of synthetic chemicals, at a time when the United States was dependent upon Germany for many drugs and dyes. $\mathrm{He}$ is now recognized as one of the outstanding authorities in the United States in organic chemistry, especially in the field of polymers, and for his extensive knowledge of organic chemical reactions. He is also a leader in the development of synthetic methods for making organic compounds, and early in his career at the University of IIlinois began manufacturing chemicals needed for research there and elsewhere. One contribution in this latter field was the production of pure amino-acids, which have served brilliantly in vitamin studies and determinations of essentials of diet. The amino-acids also are used for intravenous feeding of persons unable to tolerate proteins. Other work by Prof. Marvel has dealt with the relationship of hydrogen bonding and solubility behaviour, the synthesis and rearrangement of polyenes and polyines, association of free radicals, and other research fields. Prof. Marvel was born at Waynesville, Ill., on September 11, 1894, and received his bachelor of arts degree from Illinois Wesleyan University in 1915. He was a student of Dr. A. W. Homberger, Illinois Wesleyan, and of the late Prof. W. A. Noyes, at the University of Illinois. $\mathrm{He}$ has been associated with the editorial board of "Organic Syntheses" since 1923, and with the Journal of Organic Chemistry since its founding. $\mathrm{He}$ is a member of the National Academy of Sciences, and was chairman of Section B-3, National Defense Research Committee, during most of 1941 and 1942.

\section{Tannic Acid and Burns}

The impression that tannic acid is a safe and reliable dressing for burns is nowadays so widespread that there will be much interest in recent experimental evidence suggesting that tannic acid should be abandoned because of the risk of the damage to the liver which it may cause. S. L. Rae and A. W. Wilkinson (The Lancet, March 11, 1944, p. 332) studied, by the lævulose-tolerance test, the liver function of 27 children, aged twelve years or less, who had been burned or scalded. Of these children, 12, who had bums covering an average of 17 per cent of the body surface, were treated with 2 per cent gentian violet followed by silver nitrate; and 8 of them, whose burns were smaller, covering an average of 5 per cent of the body surface, were 